\title{
Publication rate of paper and podium presentations from the European Section of the Cervical Spine Research Society Annual Meeting
}

\author{
T. Janssen ${ }^{1}$ R. Bartels ${ }^{2}$ B. Lind ${ }^{3,4}$ - C. Villas Tome ${ }^{5}$ C. L. A. Vleggeert-Lankamp ${ }^{1}$
}

Received: 24 September 2015/Revised: 11 January 2016/ Accepted: 15 January 2016/Published online: 11 February 2016 (C) The Author(s) 2016. This article is published with open access at Springerlink.com

\begin{abstract}
Purpose The Cervical Spine Research Society Europe (CSRS-E) actively promotes scientific activities, the annual meeting being the most evident of them. The publication rate of oral and poster presentations at the annual meeting could be a measure for the success of the promotional activities. The publication rates of abstracts presented at the annual European meetings of the CSRS are unknown. The quality of the abstracts presented at a conference is reflected by the publication rate. A high publication rate is usually interpreted as representative of high scientific value of the conference.

Methods Poster and podium presentations from the 2007 to 2012 annual meetings were identified. Pubmed was used to search for the abstract title and/or the combination of authors to verify whether the data were published in a peerreviewed journal. Abstracts were considered published if
\end{abstract}

R. Bartels, B. Lind, C. Villas Tome, C. L. A. Vleggeert-Lankamp: current members of the Scientific Program Committee of the CSRS Europe.

C. L. A. Vleggeert-Lankamp

cvleggeert@lumc.nl

1 Department of Neurosurgery, Leiden University Medical Centre (LUMC), P.O. Box 9600, 2300 RC Leiden, The Netherlands

2 Department of Neurosurgery, Radboud University Medical Centre, Nijmegen, The Netherlands

3 Department of Orthopaedics, Institute of Clinical Sciences at Sahlgrenska Academy, University of Gothenburg, Göteborg, Sweden

4 Spine Center Göteborg, Göteborg, Sweden

5 Department of Orthopaedics, University of Navarra, Pamplona, Spain the data presented at the meeting were identical to that in the publication. The journals in which the data were published were identified, as well as the origin of the research centre.

Results From 2007 to 2012826 abstracts were featured at the CSRS Europe annual meetings. There were 236 podium presentations and 590 poster presentations. $42 \%$ of the podium presentations resulted in a publication, and $28 \%$ of the poster presentations led to a publication. Overall, $32 \%$ of accepted abstracts effectuated a publication in a peerreviewed scientific journal. Abstracts from European research groups had a publication rate of $29 \%$ compared to $34 \%$ for abstracts from non-European research groups. Spine, European Spine Journal, Journal of Spinal Disorders and Techniques and J Neurosurgery Spine were the most common publication journals for the abstracts. The mean impact factor of the journals in which was published was 2.2 .

Conclusion $42 \%$ of the abstracts that were accepted for podium presentation at the CSRS Europe resulted in a publication in peer-reviewed MEDLINE indexed journals. Publication rates are at the high end of the publication rate spectrum of abstracts accepted for European scientific meetings.

Keywords Cervical Spine Research Society · Publication rate Annual meeting $\cdot$ Poster presentations $\cdot$ Podium presentations

\section{Introduction}

The Cervical Spine Research Society Europe (CSRS-E) promotes that everyone involved in the cure and care of patients suffering from any disorder of the cervical spine 
has knowledge of the basics of the treatment of disorders of the cervical spine (from a surgeons' perspective) to give patients the best treatment possible. The CSRS Europe facilitates the dissemination of knowledge of new, scientifically proven developments in this field.

The annual meeting of the CSRS-es offers a podium for those researchers dedicated to discussion of research relating to exclusively the cervical spine. In order to keep a high quality level of the meetings, abstracts submitted to the CSRS annual meeting are subjected to blinded peerreview by the Scientific Program Committee. This committee consists of members of the board of the CSRS-es who are specialized in cervical spine surgery and research. Abstracts selected for podium or paper presentations are deemed to be of high quality and impact.

The goal of scientific meetings is to share research findings and offer a podium for scientific debate. Preferably, research findings that are not published (yet) are presented and discussed. This not only serves as a platform for researchers to update their knowledge on several topics, but it also offers the presenting authors some kind of 'peerreview' prior to preparing the results for publication. Ideally, the results presented at the scientific meeting should be optimized with the comments and be published as a fulltext article in scientific journals.

The podium is open to cervical spine research workers from all over the world, so non-European (aspirant) members of the CSRS US and CSRS Asia Pacific are also invited to present their work at this meeting. Abstracts of the oral presentations are published in the European Spine Journal.

The strength of a meeting may be assessed by the rate of the subsequent full-text peer-reviewed publication of the abstracts presented. Therefore, several authors investigated the publication rate of the presented papers during meetings (Table 1). Likewise, the American section of the Cervical Spine Research Society (CSRS-US) published a paper on publication rates of paper presentations in Spine in May 2015 [1]. This inspired us to assess what percentage of abstracts accepted for presentation at the annual meeting of the CSRS Europe resulted in publications in peer-reviewed journals. The abstracts of the CSRS-es annual meetings of 2007-2012 were evaluated for publication.

\section{Materials and methods}

The presentation abstracts (podium and poster) from the 2007 to 2012 CSRS Europe annual meetings were evaluated. For each abstract, a PubMed search was performed up to July 2015 to determine whether a full-text publication was present. Searches included the names of the authors and key words derived from the title of the study. If a match was not found, it was assumed that the article was not published in a MEDLINE-indexed journal. Abstracts were considered published if the data presented at the meeting were identical to that in the publication. A minimal follow-up period of 3 years was chosen since prior studies suggested that the majority of full-length articles were to be published within this time frame [2]. The number of abstracts that had led to a full text publication in a peer reviewed journal was scored and divided by the total number of abstracts that were accepted in that year, which led to the publication rate in that particular year. We did so for the abstracts accepted for oral presentation and poster presentation separately.

\section{Impact factor}

The journals that the full text articles were published in were scored. The Impact factor of the journals was determined using the journal citation reports (https://adminapps.webofknowledge.com/JCR/JCR?SID=VIDgGIEHn JmbPab6Em3). An average impact factor was calculated. The impact factor for those journals of which no ranking could be found, was set to zero.

Table 1 Publication rates

\begin{tabular}{|c|c|c|c|c|}
\hline & & $\begin{array}{l}\text { Overall publication rate } \\
\text { (\%) (impact factor) }\end{array}$ & $\begin{array}{l}\text { Oral presentation } \\
\text { rate }(\%)\end{array}$ & $\begin{array}{l}\text { Poster presentation } \\
\text { rate }(\%)\end{array}$ \\
\hline CNS and AANS [2] & 2003-2005 & 32 & 41 & 29 \\
\hline JOA [3] & 2006-2007 & 26 (IF 2.5) & 26 & 24 \\
\hline JOAR [3] & 2006-2008 & 50 (IF 3.5) & & \\
\hline SSE [4] & 2000-2003 & 38 (IF 1.8) & 48 & 31 \\
\hline EPOS [5] & 2006-2008 & 37 (IF 1.7) & & \\
\hline AAOS [6] & 2001 & 49 & 52 & 47 \\
\hline
\end{tabular}

CNS Congress of Neurological Surgeons, USA, AANS American Association of Neurological Surgeons, USA, JOA Japanese Orthopaedic Association, JOAR Japanese Orthopaedic Association Research meeting, SSE Spine Society Europe, EPOS European Paediatric Orthopaedic Society, AAOS American Academy of Orthopaedic Surgeons 


\section{Origin of articles}

The origin of the articles was evaluated and the percentage of European and non-European abstracts leading to full text articles in peer-reviewed journals was assessed.

\section{Statistical analysis}

Chi Square tests were used to compare the publication rates per year. The Chi Square test was used to compare the publication rates of European and non-European abstracts. Statistical significance was set at $P$ value of less than 0.05 . The statistical program used was SPSS version 22 .

\section{Results}

\section{Publication rate}

The six annual meetings contained in total 826 abstracts (Table 2). 236 abstracts were elected for podium presentations (Table 3), while 590 abstracts were chosen for poster presentation (Table 4). In the years 2008 and 2012, in which the annual CSRS-es meeting was part of the 'Spineweek' combined annual meetings, the numbers of poster presentations were considerably higher than in other years.

The publication rate for the podium presentation abstracts varied from 40 to $46 \%$ with a mean of $42 \%$ (Table 3). The publication rate for the poster presentation abstracts varied from 21 to $36 \%$ with a mean of $28 \%$ (Table 4). The mean publication rate was $32 \%$ (Table 2). There was no statistically significant difference between the publication rates per year $(P=0.378)$.

\section{Citation index of journals}

The majority of full text published articles were accepted in Spine (26 \%), the European Spine Journal (26\%), The Journal of Spine Disorders and Techniques (10\%), and

Table 2 Publication rate per year for podium and poster presentations combined

\begin{tabular}{lcccl}
\hline Year & Total & Published & Unpublished & Publication rate $(\%)$ \\
\hline 2007 & 119 & 41 & 78 & 34.5 \\
2008 & 150 & 52 & 98 & 34.7 \\
2009 & 126 & 48 & 78 & 38.1 \\
2010 & 137 & 37 & 100 & 27.0 \\
2011 & 104 & 33 & 71 & 31.7 \\
2012 & 190 & 55 & 135 & 28.9 \\
Total & 826 & 266 & 560 & 32.2 \\
\hline
\end{tabular}

Table 3 Publication rate for podium presentations

\begin{tabular}{lcccl}
\hline Year & Total & Published & Unpublished & Publication rate $(\%)$ \\
\hline 2007 & 38 & 17 & 21 & 44.7 \\
2008 & 37 & 17 & 20 & 46.0 \\
2009 & 39 & 17 & 22 & 43.6 \\
2010 & 43 & 17 & 26 & 39.5 \\
2011 & 40 & 16 & 24 & 40.0 \\
2012 & 39 & 16 & 23 & 41.0 \\
Total & 236 & 100 & 136 & 42.4 \\
\hline
\end{tabular}

Table 4 Publication rate for poster presentations

\begin{tabular}{lrccl}
\hline Year & Total & Published & Unpublished & Publication rate $(\%)$ \\
\hline 2007 & 81 & 24 & 57 & 29.6 \\
2008 & 113 & 35 & 78 & 31.0 \\
2009 & 87 & 31 & 56 & 35.6 \\
2010 & 94 & 20 & 74 & 21.3 \\
2011 & 64 & 17 & 47 & 26.6 \\
2012 & 151 & 39 & 112 & 25.8 \\
Total & 590 & 166 & 424 & 28.1 \\
\hline
\end{tabular}

The Journal of Neurosurgery Spine (8\%) (186 of 266 publications; Table 5). The impact factor of the journals in which the articles were published appeared to be 2.2. For only a few articles the ranking was not available, and only a minority of journals had a low ranking score (below 1.5).

\section{Origin of abstracts}

533 of the $826(65 \%)$ submitted abstracts came from a non-European source. Especially Japan was represented with a great number of abstracts. The other 293 abstracts (36\%) originated from a European country. The nonEuropean abstracts had a publication rate of $34 \%$ (182/ 533) compared to $29 \%$ (84/293) for European abstracts. There was no statistically significant difference in publication rate for European and non-European abstracts $(P=0.107$, Table 6).

\section{Discussion}

The CSRS-E has an annual meeting that serves as a podium for discussion of high standard research concerning the cervical spine. This is reflected by a publication rate of $42 \%$ for podium presentations between 2007 and 2012, and a mean impact factor of the journals the abstracts were published in of 2.2. In comparison to publication rates of other European meetings (Table 1), this percentage is at the high end of the spectrum. 
Table 5 Journals publishing poster and podium presentations

\begin{tabular}{|c|c|c|}
\hline Journal title & Number of publications $(N=560)$ & Impact factor \\
\hline Spine & 70 & 2.3 \\
\hline European Spine Journal & 69 & 2.1 \\
\hline Journal of Spinal Disorders and Techniques & 26 & 2.2 \\
\hline J Neurosurgery Spine & 21 & 3.7 \\
\hline The Spine Journal & 9 & 2.4 \\
\hline Acta Neurochirurgica & 5 & 1.8 \\
\hline Asian Spine Journal & 5 & \\
\hline Neurosurgery & 5 & 3.6 \\
\hline Journal of Bone and Joint Surgery & 4 & 3.3 \\
\hline Journal of Clinical Neuroscience & 3 & 1.4 \\
\hline Journal of Orthopaedic Surgery & 3 & 1.4 \\
\hline PLoS One & 2 & 3.2 \\
\hline SAS Journal & 2 & \\
\hline Spinal Cord & 2 & 1.8 \\
\hline Turkish Neurosurgery & 2 & 0.6 \\
\hline Acta Medica & 1 & 0.4 \\
\hline Acta Orthopaedica Belgica & 1 & 0.7 \\
\hline Acta Orthopedica & 1 & 2.8 \\
\hline Advances in Orthopedics & 1 & \\
\hline BMC Neuroscience & 1 & 3.1 \\
\hline British Journal of Sports Medicine & 1 & 5 \\
\hline Cell Transplantation & 1 & 3.1 \\
\hline Clinical Neurology and Neurosurgery & 1 & 1.1 \\
\hline Clinical Neurophysiology & 1 & 3.1 \\
\hline European Journal of Applied Physiology & 1 & 2.2 \\
\hline European Journal of Orthopaedic Surgery and Traumatology & 1 & \\
\hline European Journal of Pain & 1 & 2.9 \\
\hline European Medicine Journal & 1 & \\
\hline European Radiology & 1 & 4 \\
\hline Indian Journal of Orthopaedics & 1 & 0.6 \\
\hline Journal of Chiropractic Medicine & 1 & \\
\hline Journal of Korean Neurosurgical Society & 1 & 0.6 \\
\hline Journal of Pediatric Orthopedics & 1 & \\
\hline Journal of Spinal Cord Medicine & 1 & 1.3 \\
\hline Journal of Tissue Engineering and Regenerative Medicine & 1 & 5.2 \\
\hline Magnetic Resonance Imaging & 1 & 2.1 \\
\hline Manual Therapy & 1 & 1.7 \\
\hline Modern Rheumatology & 1 & 2.4 \\
\hline Modern Rheumatology/The Japan Rheumatism Association & 1 & \\
\hline NeuroImage & 1 & 6.4 \\
\hline Neurologica Medica Chirurgica & 1 & \\
\hline Neuroscience Letters & 1 & 2 \\
\hline Neurosurgical Review & 1 & 2.2 \\
\hline Orthopedics & 1 & 1 \\
\hline Osteoarthritis Cartilage & 1 & \\
\hline Pain Physician & 1 & 3.5 \\
\hline Patient Safety in Surgery & 1 & \\
\hline SpringerPlus & 1 & \\
\hline
\end{tabular}


Table 5 continued

\begin{tabular}{lcc}
\hline Journal title & Number of publications $(N=560)$ & Impact factor \\
\hline Studies in Health Technology and Informatics & 1 & 1 \\
The Open Orthopaedics Journal & 1 & 2.9 \\
World Neurosurgery & 1 & 0.5 \\
Zeitschrift fur Orthopädie und Unfallchirurgie & 1 & 2.2 \\
Zentralblatt fur Neurochirurgie & 266 \\
Total & 2.2 \\
\hline
\end{tabular}

Table 6 Origin of abstracts and publication rate

\begin{tabular}{lcccl}
\hline Origin/type of presentation & Total & Published & Unpublished & Publication rate (\%) \\
\hline Non-European/podium & 160 & 68 & 92 & 42.50 \\
European/podium & 76 & 32 & 44 & 42.10 \\
non-european/poster & 373 & 114 & 259 & 30.60 \\
European/poster & 217 & 52 & 165 & 24.00 \\
\hline
\end{tabular}

The CSRS-US meetings reported an overall publication rate of $66 \%$ for podium presentations submitted between 2007 and 2011 [1]. In general, the publication rates of US meetings are higher than the publication rates of European meetings [5]. It can be hypothesized that the contributions of authors to their congresses are of a higher level, leading to a higher chance of being published. The CSRS-US meeting has more attendants and more abstracts sent in [5]; this can lead to a higher quality of the abstracts that are elected for podium presentation. The majority of full-text published articles from the current overview were accepted in Spine (26\%), the European Spine Journal (26\%), The Journal of Spine Disorders and Techniques (10\%), and The Journal of Neurosurgery Spine (8\%). Only one of these is a European Spine Journal.

The mean impact factor of the articles that were published in peer-reviewed journals was 2.2, which is high in comparison to the mean impact factor reported by overviews of other European spine congress accepted abstracts (Table 1). Where the publication rate reflects the scientific value of the presented abstracts, the impact factor reflects the measure of attractiveness of the presented knowledge for a broad audience. For research focusing on the cervical spine, which in general is interesting to only a limited audience, this is a remarkable result.

As expected, the overall publication rate for oral presentations was higher that that for poster presentations, in line with the findings of Patel [2]. This is due to the selection process of the Scientific Program Committee that elects the highest quality abstracts for oral presentation. Those high quality abstracts are more likely to pass the peer-review for publication by scientific journals.

Observing the origin of the abstracts selected for presentations in the CSRS-es annual meeting it is noticed that a lot of abstracts originate from non-European countries. The origin of the research work did however not effectuate the publication rate.

A limitation to this study is that the reason that an abstract did not result in a peer-reviewed publication is not known to the authors of the current paper. It is presumed that at some point in the publication process, the authors stopped their efforts to get the results published. If we assess the strength of a meeting by the rate of the subsequent full-text peer-reviewed publication of the abstracts presented, the whereabouts of this process are preferably known in the determination of the publication rate. Some congress organizations offer the presenters of abstracts to send the full-text article to a particular journal. This logically increases the publication rate, though it does not mean that the full-text paper is published automatically.

The abstracts that are elected in the peer-review process of the program committee to be presented in the CSRS Europe meeting were esteemed to be of considerable interest to the audience. It is conceivable that the program committee will offer their assistance to future presenters to have their results published in full-text peer-reviewed journals. This would lead to the offering of this research work to a broader audience, which presumably lifts cervical spine research to a higher level.

In conclusion, the publication rate for the CSRS Europe abstracts of the 2007-2012 annual meetings was $42 \%$ for the oral presentations and $28 \%$ for the poster presentations. Apparently, the manuscripts were published in for spinal surgeons very attractive journals in which landmark papers are generally published. This meeting therefore serves as an excellent podium for cervical spine research workers to present and discuss their scientific work. 


\section{Compliance with ethical standards}

Conflict of interest No funding was received. No financial support and industry affiliations to disclose.

Open Access This article is distributed under the terms of the Creative Commons Attribution 4.0 International License (http://crea tivecommons.org/licenses/by/4.0/), which permits unrestricted use, distribution, and reproduction in any medium, provided you give appropriate credit to the original author(s) and the source, provide a link to the Creative Commons license, and indicate if changes were made.

\section{References}

1. Okafor L, Frost C, Mesfin A (2015) Publication rate of paper presentations from the cervical spine research society annual meeting. Spine 40(10):699-702
2. Patel AJ, Cherian et al (2011) Publication patterns of oral and poster presentations at the annual meetings of the congress of Neurological Surgeons and the American Asscociation of Neurological Surgeons. J Neurosurg 115:1258-1261

3. Ohtori S, Kubota G, Inage K et al (2013) English publication rate of 3205 abstracts presented at the annual meeting of the Japanese orthopaedic association and the annual research meeting of the Japanese orthopaedic association. J Orthop Sci 18:1031-1036

4. Schulte TL, Huck K, Osada N et al (2012) Publication rate of abstracts presented at the annual congress of the Spine Society of Europe (years 2000-2003). Eur Spine J 21:2105-2112

5. Kleine-Konig M, Schulte TL et al (2014) Publication rate of abstracts presented at European paediatric orthopaedic society annual meetings 2006-2008. J Pediatr Orthop 34:e33-e38

6. Donegan DJ, Kim TW, Lee G (2010) Publication rates of presentations at an annual meeting of the American academy of Orthopaedic surgeons. Clin Orthop Relat Res 468:1428-1435 